\title{
e-Nabız Uygulamasını Değerlendirmek İçin Kullanılan Yeni Bir Araç: Mobil Uygulama Derecelendirme Ölçeği
}

\author{
Sezer KORKMAZ* \\ Gamze ARIKAN**
}

Geliş Tarihi (Received): 22.02.2021 - Kabul Tarihi (Accepted): 02.04.2021

\section{$\ddot{O} \mathbf{z}$}

Sağlık için mobil uygulamaların kullanımı son yıllarda giderek artmıştır. Mobil sağlık uygulamaları, sağlık hizmetlerine ve bilgilerine erişimi artırmakta, sağlıkla ilgili bilgilerin toplanmasını ve analizinin yapılmasını sağlamaktadır. Bu çalışmanın amacı, Ankara Hacı Bayram Veli Üniversitesi, Sağlık Yönetimi bölümü öğrencilerinin, e-Nabız mobil sağlık uygulamasına yönelik bakış açıları ve kalite değerlendirmelerini ortaya koymak ve uygulamanın sürekli kullanım niyetini incelemektir. E-nabız mobil sağlık uygulamasının kalite değerlendirilmesi için Mobil Uygulama Derecelendirme Ölçeği (MARS) kullanılmıştır. Bununla beraber ankete sürekli kullanım niyeti ölçeği de eklenmiştir. Çalışmada 297 öğrenciye anket uygulanmıştır. Verilerin analizinde parametrik testler kullanılmıştır. Mobil uygulama derecelendirme ölçeğinin sosyo demografik değişkenlere göre farklılık gösterip göstermediğini ölçmek için "Bağımsız İki Örneklem T-Testi" ve "Varyans (ANOVA) Analizinden" yararlanılmıştır. Ayrıca mobil uygulama derecelendirme ölçeği ile sürekli kullanım niyeti arasındaki ilişkinin varlığını ve yönünü tespit etmek amacıyla "Pearson Korelâsyon" analizi uygulanmıştır. Pearson Korelâsyon testi sonuçlarına göre mobil uygulama derecelendirme ölçeği ile sürekli kullanım niyeti arasında pozitif yönde anlamlı bir ilişki olduğu ortaya konulmuştur. Bu doğrultuda öğrencilerin e-nabız uygulamasını olumlu değerlendirdikleri ve beraberinde uygulamayı kullanmaya devam edecekleri belirlenmiştir.

Anahtar Kelimeler: Sağlık, Mobil sağlık uygulaması, e-Nabız, Mobil uygulama derecelendirme ölçeği

\section{A New Tool Used To Evaluate The e-Pulse Application: Mobile Application Rating Scale}

\begin{abstract}
The use of mobile applications for health has been increasing in recent years. Mobile healthcare applications increase access to health services and information, and enable the collection and analysis of health-related information. The purpose of this study is to reveal the perspectives and quality evaluations regarding the e-Pulse mobile health application and is to examine continued intention to use of the application for Ankara Hac1 Bayram Veli Üniversity, Departmen of Health Care students'.Mobile App Rating Scale (MARS) is used to evaluate the quality of the e-pulse mobile health application. In addition, continued intention to use scale was added to the questionnaire. In the study conducted surveys of 297 students. Parametric tests were used in the analysis of the data. Accordingly, "Independent Two-Sample T-Test" and "Variance (ANOVA) Analysis" were used to measure whether the mobile application rating scale varies according to socio-demographic variables. In addition, "Pearson Correlation" analysis was applied in order to determine the existence and direction of the relationship between the mobile application rating scale and continued intention to use. Pearson Correlation test results show that there is a positive relationship between mobile app rating scale and continued intention to use. Accordingly, it can be said that the students will continue to use the application with their good evaluation of the e-pulse application.
\end{abstract}

Keywords: Health, Mobile health application, e-Pulse, Mobile application rating scale

\footnotetext{
* Prof. Dr., Ankara Hacı Bayram Veli Üniversitesi, İktisadi ve İdari Bilimler Fakültesi, Sağlık Yönetimi Bölümü, sezer.korkmaz@hbv.edu.tr, orcid.org/0000-0001-9393-5136.

** Arş. Gör., Ankara Hacı Bayram Veli Üniversitesi, İktisadi ve İdari Bilimler Fakültesi, Sağlık Yönetimi Bölümü, gamze.arikan@hbv.edu.tr, orcid.org/0000-0003-2911-2412.
} 


\section{Giriş}

Son y1llarda bilgi ve iletişim teknolojilerinde yaşanan yeniliklerin, bireylerin sağlı̆̆ını geliştirmek için kullanıldığı görülmektedir. Özellikle akıllı telefonlarda, sağlık bilgisine sahip bireylere ulaşmak için yenilikçi stratejiler geliştirilmektedir. Taşınabilirliği ve sürekli kullanılabilirliği nedeniyle, akıllı telefonlar birçok mobil uygulamayı beraberinde getirmektedir (Viswanath ve diğerleri, 2015, s. 354). Dünya sağlık örgütü mobil sağlık kavramını, sağlık ve sağlıkla ilgili alanları destelemek adına dijital sağlığın bütünleyici bir parçası olarak tanımlamaktadır (Enginkaya, 2019, s. 416). Mobil ve giyilebilir sağlık teknolojilerinin kullanımı, sağlı gözetiminin zamansal, mekânsal ve kişilerarası niteliğini ortaya koymaktadır. Sağlıkla ilgili veriler, kullanıcıların ilgili uygulamada oturum açtıklarında mobil cihazlarından kolayca ve sıklıkla toplanabilmektedir. Bu cihazlar, sadece kullanıcılara değil, sağlık ve kamu sağlığı çalışanlarına da bireylerin sağlıkla ilgili alışkanlıklarını izlemek ve ölçmek için benzersiz bir firsat sunmaktadır (Lupton, 2013, s. 395). Mobil uygulamalar, bireylerin alışkanlıklarından dolayı geliştirdikleri sağlıklarını tehdit eden hatalı davranışlarının iyileştirilmesi ve geliştirilmesinde stratejik bir araçtır (Singh vd., 2014, s. 607). Fitness ve sağlık, sigarayı bırak sağlıklı yaşa, beslenme, anında kalp hızı monitörü, e-nabız, nabız takibi, Merkezi Hastane Randevu Sistemi (MHRS mobil) gibi uygulamalar mobil sağlık uygulamalarına örnek olarak verilebilir. Bu doğrultuda mobil sağlık uygulamaları ile birçok veri toplanmakta ve kişiselleştirilmiş geri bildirim sağlanmaktadır.

Çalışmada, e-Nabız mobil sağlık uygulaması ele alınmaktadır. Bu bağlamda Ankara Hacı Bayram Veli Üniversitesi Sağlık Yönetimi bölümünde okuyan öğrencilerin, e-Nabız mobil sağlık uygulamasına yönelik bakış açılarının ve uygulamaya ilişkin değerlendirmelerinin ortaya konulması amaçlanmıştır.

\section{Kavramsal Çerçeve}

Günümüzde modern tıp, mobil dönüşümün zirvesindedir. Mobil bilgi işlem ve iletişim teknolojilerinin uygulanması, sağlık kurumları ve halk sağlığı alanlarında hızla genişlemektedir (Free vd., 2010, s. 250). Cep telefonlarının ve diğer teknolojilerin sağlık için kullanımı esağlığın bir uzantısı olan mobil sağlıktır (mHealth) ve sağlık sektöründe mobil cihazların entegrasyonunu kapsar (Mechael, 2009, s. 105). Mobil sağlık, sağlık hizmetleri için ortaya çıkan mobil iletişim ve ağ teknolojileri olarak tanımlanır (Kyriacou vd., 2007, s. 218). Bir başka ifadeyle mobil sağlık veya "mHealth", akıllı telefonlar ve tabletler gibi taşınabilir cihazların tanı, tedavi veya genel sağlık ve refahın desteklenmesi gibi tıbbi amaçlarla kullanılmasıdır 
(Hamel vd., 2014, s. 373). Kullanıcılar, genellikle etkileşimli anketlerden, mobil cihaza bağlı tıbbi cihazlardan kamera, hareket sensörü veya mikrofon gibi cihazın kendi işlevlerinden veri toplayan yazılım uygulamaları aracılığıyla mobil cihazlarla arayüz oluşturabilir. Uygulamalar, özelleştirilmiş tanılar ve tedavi önerileri oluşturmak için tıbbi algoritmalar veya hesap makineleri kullanarak bu verileri işleyebilir. Mobil cihazlar, genellikle hastanelerde veya doktorların muayenelerinde kullanılan cihazlardan daha ayrıntılı hasta verisi toplamayı mümkün kılar ve bu verilerin farklı kullanıcılar arasında mevcut mesafelerini aşarak tıbbi bilgilere ve uzman bakımına eşit erişim sağlar (Hamel vd., 2014, s. 374; Istepanian ve Lacal, 2003, s. 1415). Daha ötesi toplumdaki hastalar tarafından sağlık davranışı değişikliğini ve kronik hastalık yönetimini desteklemek amacıyla kullanılır (Free vd., 2010, s. 250). Conroy ve arkadaşları (2014, s. 650), mobil sağlık uygulamalarının sağlık davranışı teorilerine açıkça dayanması gerektiğini ifade etmişlerdir. Örneğin, özellikle sigarayı bırakmak ve bu konuda davranış değişikliği oluşturmak isteyen bireylere, gün boyunca sigarayı bırakma motivasyonlarını sürdürmek için tasarlanmış mesajlar gönderilebilir (Free vd., 2013). Wang ve arkadaşlarının (2020, s.5) yaptıkları bir diğer çalışmada da en az bir davranışsal değiş̧ikliği içeren fiziksel aktivitenin mobil sağlık uygulamasında yer almasının gerekli olduğu vurgulanmıştır. Çalışmalarında, Çin'de popüler olan fiziksel aktivite mobil sağlık uygulamalarının, işlevsellik bakımından en yüksek puanı aldığını saptamışlardır. De Mattos ve Gondim (2016, s. 26) yaptıkları çalışmada, sağlık için mobil uygulamaların, doktorlar, hemşireler, hastalar ve hatta sağlıklı insanlar gibi farklı kitlelere hitap ettiğini ifade etmişlerdir. Ayrıca 2020'nin sonuna gelindiğinde, sağlıkla ilgili olarak, yüz milyonlarca cihazın makineden makineye teknolojisi (Machine to Machine, M2M) ile çalışacağını vurgulamışlardır.

Ülkemizde Sağlık Bakanlığı tarafından geliştirilen kişisel sağlık uygulaması olan eNabız, sağlık kuruluşlarından toplanan verilerin bireylerin internet ve mobil cihaz üzerinden ulaşabilecekleri dijital bir uygulamadır. Türkiye'nin ' güvenilir kişisel sağlık sistemi olarak uygulamaya konulan e-Nabız bireylerin, muayene, tetkik ve tedavilerini nerede yaptığına bakılmaksızın, tüm sağlık bilgilerini yönetilebileceği, tıbbi özgeçmişe tek bir yerden ulaşılabilecekleri, kişisel bir sağlık kaydı sistemidir. E-nabız sistemi ile bireylerin sağlık kurum ve kuruluşlarında gerçekleştirilen tüm muayene, tetkik ve radyolojik görüntüleme, yazılan reçeteler, ilaçlara ait tüm veriler ve geçirilen operasyonlar hakkındaki bilgilere 7 gün 24 sat erişebilmesine imkân sağlanmaktadır. Ayrıca, bu sistemle bireylerin, sağlık hizmet sunumuna dâhil olması, katılımın, hizmet sürdürülebilirliğinin ve sağlık okuryazarlığının artması hedeflenmektedir (Sağlık Bakanlı̆̆ı, 2020; Demir, 2017). Free ve arkadaşları (2010, s. 250), 
yaptıkları çalışmanın sonucunda mobil sağlık uygulamalarının sistematik olarak gözden geçirilmesinin önemli olduğunu vurgulayarak, çok çeşitli sağlık ve sağlık hizmeti sonuçlarını iyileştirmek için mobil bilgi işlem ve iletişim teknolojilerinin kullanılmasının gerekliliğinden bahsetmişlerdir. Uyar (2019, s. 700) çalışmasında, mobil uygulamaları kolaylıkla kullanan kişilerin, bu uygulamalardan daha fazla faydalandıklarını ifade etmiştir. Ayrıca çalışmasında algılanan fayda ile kullanım niyeti arasında anlamlı bir ilişki olduğunu ve buna göre uygulamaların faydalı görülmesi arttıkça kullanıma yönelik isteğin de arttığını saptamıştır. Yeşiltaş (2018, s. 293) yaptığı anket çalışmasında e-Nabız kullanıcılarının, uygulamayı yararlı bulduğunu, kullanımının basit ve gerekli olduğunu, uygulamanın sağlık hizmetlerinden yararlanmayı kolaylaştırdığını ifade ettiklerini belirtmiştir. Ancak aynı çalışmanın bir diğer sonucu katılımcıların \%62'sinin e-Nabız uygulamasından haberdar olmadığını göstermiştir. Bir başka çalışmada Kıraç ve Yılmaz (2019, s. 1663) ise, mobil sağlık uygulaması olan e-Nabız'ın farkındalık düzeyinin düşük çıktığını saptamışlardır. Farkındalık düzeylerini artırmak için kitle iletişim araçları ile daha fazla tanıtım yapılabileceğini ifade etmişlerdir. E-nabız uygulamasının yaygınlaşması, bireylerin sağlı̆̆ını ve sağlıkla ilgili verilerin izlenmesini kolaylaştıracak, hastaların bakım ve sağlığının kalitesini yükseltecektir (Kıraç ve Yılmaz, 2019, s. 1666). Bu yüzden bireylerin e-Nabız uygulamasını nasıl değerlendirdikleri ve bu konudaki farkındalık düzeylerinin belirlenmesi önemlidir.

\section{Araştırma}

\subsection{Araştırmanın Amacı, Kapsamı ve Yöntemi}

Araştırma için Ankara Hacı Bayram Veli Üniversitesi Etik Komisyonundan etik yönden uygunluk alınmıştır (2020-46/ 04-28.04.2020). Bununla birlikte araştırmanın yapıldığı Sağlık Yönetimi bölümü öğrencilerine uygulanan anket için de Sağlık Yönetimi bölüm başkanlığı tarafından gerekli izin de alınmıştır. Katılımcılara çalışma hakkında sözlü olarak bilgi verilmiştir.

Çalışmada, Ankara Hacı Bayram Veli Üniversitesi Sağlık Yönetimi bölümünde okuyan öğrencilerin e-Nabız mobil sağlık uygulamasına yönelik görüşleri ve uygulamanın değerlendirilmesine ilişkin bakış açıları ortaya konulmaya çalışılmıştır. Araştırmada, öğrencilerin e-Nabız uygulamasına yönelik değerlendirmelerini ölçmek için Stoyanov ve diğerleri (2015) tarafından geliştirilen 23 ifadeden oluşan Mobil Uygulama Derecelendirme Ölçeği (MARS) kullanılmıştır. Ölçek; katılım, işlevsellik, estetik, bilgi kalitesi ve öznel kalite olmak üzere beş boyuttan oluşmaktadır. Ayrıca Venkatesh ve Goyal (2010, s. 291) tarafından geliştirilen, Güler (2019, s. 175) tarafından Türkçe'ye uyarlanan, 6 ifadeden oluşan sürekli 
kullanım niyeti ölçeği ankete eklenmiştir. Bu boyutlar 5'li Likert tipi ölçek kullanılarak ölçülmüştür. Araştırma için örneklem seçilmemiş tüm öğrencilere ulaşılmaya çalışılmıştır. Bölümde öğrenim gören toplam 400 öğrenci vardır ve öğrencilerin 297'sine anket uygulanmıştır. Bu çalışmada kullanılan, ölçeklere ait Cronbach Alpha güvenirlik değerlerine Tablo 1'de yer verilmiştir.

\section{Tablo 1. Ölçeklerin Güvenilirlik Değerleri}

\begin{tabular}{|l|l|}
\hline Ölçek & Cronbach Alpha \\
\hline $\begin{array}{l}\text { Mobil Uygulama Derecelendirme } \\
\text { Ölçeği }\end{array}$ &, 963 \\
\hline Sürekli Kullanım Niyeti Ölçeği &, 638 \\
\hline
\end{tabular}

Güvenirlik analizine göre Cronbach Alpha değerleri, , $60 \leq \alpha \leq, 80$ değerler arasında oldukça güvenilir; , $80 \leq \alpha \leq 1,00$ değerleri arasında yüksek derecede güvenilirdir (Kalaycı, 2016, s. 405). Bu doğrultuda araştırmada kullanılan ölçeklerin güvenilir olduğu kabul edilebilir.

Araştırmanın hipotezleri şunlardır:

H1: Mobil uygulama derecelendirme ölçeği ile sosyo-demografik değişkenler arasında anlamlı farkl11ık vardır.

H2: Mobil uygulama derecelendirme ölçeği ile sürekli kullanım niyeti ölçeği arasında anlamlı bir ilişki vardır.

Elde edilen veri seti SPSS 23.0 istatistik paket programı yardımıyla analiz edildiğinde basıklık (kurtosis) ve çarpıklık (skewness) değerleri bakımından normal dağılım gösterdiği saptanmıştır. Dağılıma ilişkin bulgular şu şekildedir: Mobil uygulama derecelendirme ölçeğine ait basıklık değeri -,793, çarpıklık değeri ise -,276 olarak elde edilmiştir. Sürekli kullanım niyeti ölçeğine ait basıklık değeri $-1,080$ çarpıklık değeri 1,281 olarak elde edilmiştir. Literatürde basıklık ve çarpıklık değerlerinin \pm 3 aralığında olması değişkenlerin normal dağılım gösterdiği kabul edilmektedir (Kalaycı, 2016, s. 415). Sonuç olarak verilerin analizinde parametrik testlerin kullanılması uygun görülmüştür. Bu doğrultuda mobil uygulama derecelendirme ölçeğinin sosyo demografik değişkenlere göre farklılık gösterip göstermediğini ölçmek için “Bağımsız İki Örneklem T-Testi” ve "Varyans (ANOVA) Analizinden” yararlanılmıştır. Ayrıca mobil uygulama derecelendirme ölçeği ile sürekli kullanım niyeti arasındaki ilişkinin varlığını ve yönünü tespit etmek amacıyla "Pearson Korelâsyon” analizi uygulanmıştır. 


\subsection{Araştırma Bulguları}

Çalışmanın bu bölümünde katılımcıların verdikleri yanıtlara göre demografik verilerin yüzde ve frekans dağılımları Tablo 2'de gösterilmiştir.

Tablo 2. Katılımcıların Yüzde ve Frekans Dağılımları

\begin{tabular}{|c|c|c|c|}
\hline \multirow[t]{2}{*}{ Özellikler } & & \multicolumn{2}{|c|}{ Katılımeı } \\
\hline & & $\mathbf{N}$ & $(\%)$ \\
\hline \multirow[t]{2}{*}{ Cinsiyet } & Kadın & 232 & 78,1 \\
\hline & Erkek & 65 & 21,9 \\
\hline \multirow[t]{2}{*}{ Yaş } & $18-21$ yaş & 205 & 70,2 \\
\hline & $22-25$ yaş & 92 & 29,8 \\
\hline \multirow{4}{*}{ Kaçıncı Sınıf } & 1.sinif & 85 & 28,6 \\
\hline & 2.sinif & 72 & 24,2 \\
\hline & 3.sinif & 75 & 25,3 \\
\hline & 4.sinif & 65 & 21,9 \\
\hline \multirow{2}{*}{ Kronik hastalık } & Evet & 15 & 5,1 \\
\hline & Hayır & 282 & 94,9 \\
\hline \multirow[t]{2}{*}{ Kullanılan İlaç } & Evet & 25 & 8,4 \\
\hline & Hayır & 272 & 91,6 \\
\hline Toplam & & 297 & 100 \\
\hline
\end{tabular}

Çalışmaya katılan öğrencilerin \%78'i kadın, \%22'si erkeklerden oluşmaktadır. Katılımcıların yaş düzeylerinin dağılımı incelendiğinde ise \%70'i 18-21, \%30’u 22-25 yaş grubunda olduğu görülmektedir. Katılımcıların \%29'u 1.sınıf, \%24'ü 2.sınıf, \%25'i 3.sınıf ve \%22'si 4.sınıf öğrencilerinden oluşmaktadır. Öğrencilerin \%95'i herhangi bir kronik hastalığa sahip olmadığını ve \%92'si ilaç kullanmadıklarını ifade etmişlerdir.

Katılımcıların araştırma ölçeklerine ilişkin genel ortalamalarına bakıldığında en yüksek ortalamaya sahip ifade $\overline{\mathrm{x}}=4,50$ ile "Gelecekte e-Nabız uygulamasını kullanmaya devam etmeyi düşünmüyorum" olduğu belirlenmiştir. Daha sonra $\overline{\mathrm{x}}=3,41$ ortalamayla "E-nabız uygulama ekranındaki menülerin yazı tipi büyüklügü anlaşılırdır” ifadesi takip etmektedir. En düşük ortalamaya sahip ifade $\overline{\mathrm{x}}=2,38$ ile “E-nabız uygulamasının kullanımı ilginçtir”tir. Katılımcıların mobil uygulama derecelendirme ölçeğinin sosyo-demografik değişkenlere göre anlamlı bir farklılık gösterip göstermediği Bağımsız İki Örneklem t-testi ile analiz edilmiş olup, elde edilen bulgulara aşağıdaki tablolarda yer verilmiştir. Sosyo-demografik değişkenler arasında sınıf değişkeninde birden fazla grup olması nedeniyle ANOVA ile analiz edilmiştir.

Aşağıda tablo 3 'te görüldüğü üzere bağımsız iki örneklem t testi sonuçlarına göre, mobil uygulama derecelendirme ölçeğinde yer alan alt değişkenler ve sürekli kullanım niyetinin cinsiyet değişkeni arasındaki farkın istatistiksel olarak anlamlı olduğu gözlemlenmiştir 
$(\mathrm{p}<0.05)$. Bu doğrultuda kadınların erkeklere göre e-Nabız uygulamasını daha kaliteli değerlendirdikleri ve uygulamayı kullanmaya devam ettikleri söylenebilir.

Tablo 3. Mobil uygulama derecelendirme ve sürekli kullanım niyetinin cinsiyet değişkeni ile karşılaştırılması- t-testi

\begin{tabular}{|c|c|c|c|c|c|}
\hline & Cinsiyet & $\mathrm{N}$ & Ortalama & $\mathrm{t}$ & Sig. \\
\hline Katılım & $\begin{array}{l}\text { Kadın } \\
\text { Erkek }\end{array}$ & $\begin{array}{c}232 \\
65 \\
\end{array}$ & $\begin{array}{l}2,7914 \\
2,3938 \\
\end{array}$ & 1,857 & 0,67 \\
\hline İ̀şlevsellik & $\begin{array}{l}\text { Kadin } \\
\text { Erkek }\end{array}$ & $\begin{array}{c}232 \\
65 \\
\end{array}$ & $\begin{array}{l}3,1414 \\
2,5281 \\
\end{array}$ & 2,677 &, $009 *$ \\
\hline Estetik & $\begin{array}{l}\text { Kadın } \\
\text { Erkek }\end{array}$ & $\begin{array}{c}232 \\
65 \\
\end{array}$ & $\begin{array}{l}3,3200 \\
2,8047 \\
\end{array}$ & 2,134 & ,036* \\
\hline Bilgi & $\begin{array}{l}\text { Kadın } \\
\text { Erkek }\end{array}$ & $\begin{array}{c}232 \\
65 \\
\end{array}$ & $\begin{array}{l}3,2568 \\
2,6987 \\
\end{array}$ & 2,354 & ,021* \\
\hline Kullanım niyeti & $\begin{array}{l}\text { Kadın } \\
\text { Erkek }\end{array}$ & $\begin{array}{c}232 \\
65 \\
\end{array}$ & $\begin{array}{l}3,6451 \\
3,3437 \\
\end{array}$ & 2,906 &, $005 *$ \\
\hline
\end{tabular}

$* \mathrm{p}<0.05$

Çalışmada mobil uygulama derecelendirme ölçeğinde yer alan alt değişkenler ve sürekli kullanım niyetinin, ilaç kullanma değişkeniyle olan ilişkisine de bakılmıştır. Yapılan t testinin sonuçları aşağıda tablo 4 'te verilmiştir.

Tablo 4. Mobil uygulama derecelendirme ve sürekli kullanım niyetinin ilaç kullanma ile karşılaştırılmasıt-testi

\begin{tabular}{|c|c|c|c|c|c|}
\hline & İlaç kullanma & $\mathrm{N}$ & Ortalama & $\mathrm{t}$ & Sig. \\
\hline Katılım & $\begin{array}{l}\text { Evet } \\
\text { Hayır }\end{array}$ & $\begin{array}{c}25 \\
272\end{array}$ & $\begin{array}{l}3,2880 \\
2,6481\end{array}$ & 3,483 &, $001 *$ \\
\hline İşlevsellik & $\begin{array}{l}\text { Evet } \\
\text { Hayır }\end{array}$ & $\begin{array}{c}25 \\
272\end{array}$ & $\begin{array}{l}3,5040 \\
2,9570\end{array}$ & 2,480 & ,018* \\
\hline Estetik & $\begin{array}{l}\text { Evet } \\
\text { Hayır }\end{array}$ & $\begin{array}{c}25 \\
272\end{array}$ & $\begin{array}{l}3,7500 \\
3,1528\end{array}$ & 3,092 &, $003 *$ \\
\hline Bilgi & $\begin{array}{l}\text { Evet } \\
\text { Hayır }\end{array}$ & $\begin{array}{c}25 \\
272\end{array}$ & $\begin{array}{l}3,6457 \\
3,0847\end{array}$ & 3,049 &, $004 *$ \\
\hline Kullanım niyeti & $\begin{array}{l}\text { Evet } \\
\text { Hayır }\end{array}$ & $\begin{array}{c}25 \\
272\end{array}$ & $\begin{array}{l}3,8800 \\
3,5519\end{array}$ & 2,449 &, $015^{*}$ \\
\hline
\end{tabular}

$* \mathrm{p}<0.05$

Tablo 4'te görüldüğü üzere, mobil uygulama derecelendirme ölçeğinde yer alan değişkenler ve sürekli kullanım niyetinin ilaç kullanma değişkeni arasında anlamlı bir farklılık olduğu saptanmıştır $(\mathrm{p}<0.05)$. Burada ilaç kullanan öğrencilerin kullanmayanlara göre e-Nabız uygulaması hakkında bilgi sahibi oldukları ve derecelendirme ölçeği altında yer alan değişkenlerin yeterliliği konusunda farkındalıklarının yüksek olduğu belirlenmiştir. Ayrıca uygulamayı sürekli kullanma niyetlerinin de yüksek olduğu saptanmıştır. 
Diğer sosyo-demografik değişkenler; yaş, sınıf ve sahip oldukları kronik hastalıklar bakımından anlamlı bir farklılık olmadığı tespit edilmiştir. Bu yüzden H1 hipotezi kısmen kabul edilebilir bulunmuştur.

Mobil uygulama derecelendirme ölçeğinde yer alan alt değişkenlerle sürekli kullanım niyeti ölçeği arasındaki ilişkiye yönelik sonuçlara ulaşmak amacıyla "Pearson Korelâsyon Analizi” yapılmış ve analiz bulgularına aşağıdaki tablo 5 'te yer verilmiştir.

Tablo 5. Mobil Uygulama Derecelendirme ile Sürekli Kullanım Niyeti Ölçeği Arasındaki Korelâsyonlar: Pearson Korelâsyon Testi

\begin{tabular}{|c|c|c|c|c|c|}
\hline & Katılım & İșlevsellik & Estetik & Bilgi & Kullanım niyeti \\
\hline Katılım & 1,000 & $\begin{array}{c}, 843^{* *} \\
, 000 \\
\end{array}$ & $\begin{array}{c}, \mathbf{8 1 7} 7^{\text {** }} \\
, 000 \\
\end{array}$ & $\begin{array}{c}\mathbf{7 6 9}^{* * *} \\
, 000\end{array}$ & $\begin{array}{c}\mathbf{5 5 2} 2^{* *} \\
, 000 \\
\end{array}$ \\
\hline İşlevsellik & $\begin{array}{c}\mathbf{8 4 3}^{* *} \\
, 000\end{array}$ & $\begin{array}{c}1,000 \\
.\end{array}$ & $\begin{array}{c}\mathbf{, 8 9 1}^{* *} \\
, 000\end{array}$ & $\begin{array}{c}\mathbf{8 3 2}^{* *} \\
, 000\end{array}$ & $\begin{array}{c}, \mathbf{5 7 8}^{* * *} \\
, 000\end{array}$ \\
\hline Estetik & $\begin{array}{c}\mathbf{, 8 1 7}^{* *} \\
, 000\end{array}$ & $\begin{array}{c}\mathbf{, 8 9 1}^{* * *} \\
, 000\end{array}$ & 1,000 & $\begin{array}{c}\mathbf{, 8 3 8}^{* * *} \\
, 000\end{array}$ & $\begin{array}{c}\mathbf{, 5 8 1}^{* *} \\
, 000\end{array}$ \\
\hline Bilgi & $\begin{array}{c}\mathbf{7 6 9}^{* *} \\
, 000\end{array}$ & $\begin{array}{c}\mathbf{, 8 3 2}^{* *} \\
, 000\end{array}$ & $\begin{array}{c}\mathbf{, 8 3 8}^{* *} \\
, 000\end{array}$ & 1,000 & $\begin{array}{c}\mathbf{, 5 2 3}^{* *} \\
, 000\end{array}$ \\
\hline Kullanım niyeti & $\begin{array}{c}\mathbf{5 5 2}^{* *} \\
, 000\end{array}$ & $\begin{array}{c}\mathbf{5 7 8}^{* *} \\
, 000\end{array}$ & $\begin{array}{c}\mathbf{, 5 8 1}^{* *} \\
, 000\end{array}$ & $\begin{array}{c}\mathbf{, 5 2 3}^{* * *} \\
, 000\end{array}$ & $\begin{array}{c}1,000 \\
.\end{array}$ \\
\hline
\end{tabular}

Pearson Korelâsyon analizi sonucu, mobil uygulama derecelendirme değişkenleriyle sürekli kullanım niyeti ölçeği arasında pozitif yönde anlamlı, orta düzeyde bir ilişki söz konusudur. Bu doğrultuda öğrencilerin e-Nabız mobil sağlık uygulamasını katılım, işlevsellik, estetik ve bilgi kalitesi bakımından olumlu değerlendirdikleri belirlenmiştir. Dolayısıyla bu durum uygulamanın sürekli kullanımına da pozitif olarak yansımıştır. Bu bağlamda $\mathrm{H} 2$ hipotezi kabul edilmiştir.

\section{Sonuç ve Değerlendirme}

Mobil sağlık uygulamaları, küresel ölçekte kanıta dayalı sağlık bilgilerine 24 saat erişim sağlama potansiyeline sahiptir (Stoyanov vd., 2016). Kullanıcılar, sağlık bilgi ihtiyaçlarını karşılamak, kendi sağlıklarını kendi kendine yönetmek ve sağlık hizmeti sağlayıcılarıyla iletişim aracı olarak mobil sağlık uygulamalarını giderek daha fazla kullanmaktadırlar (Brown III vd., 2013, s. 1082). Amerika Birleşik Devletlerinde, Ulusal bir sağlık bilişim teknolojisinin alt yapısının hızlı bir şekilde geliştirilmesine çaba sarfedilerek, 1500'ün üzerinde yardımcı mobil tibbi uygulama geliştirilmiştir (Merrell, 2011). Ayrıca mobil sağlık uygulamaları, literatürde de pek çok çalışmanın konusu olmuştur. Arsand, Froisland, Skrovseth, Chomutare, Tatara, Hartvigsen ve Tufano (2012, s. 1201) diyabetli hastaları baz alarak yaptıkları 
çalışmalarında, söz konusu hastalara yardımcı olabilecek mobil sağlık uygulamaları üzerinde durmuşlardır. Bizim çalışmamızla da benzerlik gösteren bir diğer çalışmada üniversite öğrencilerinin mobil sağlık ve kişisel sağlık kaydı yönetimine ilişkin görüşleri ortaya konulmaya çalışılmıştır (Arslan ve Demir, 2017, s. 32). Belyaev, Sun, Ray. (2018, s. 475) ise çalışmalarında, kişisel veri sunucusu cihazlarda sağlık kayıtlarının depolanmasına ilişkin protokollerin ve tasarımların üzerinde durarak konu ile ilgili öneriler sunmuşlardır. Huy ve Vanthanh (2012, s. 26) ise çalışmalarında, mobil uygulama pradigmalarının değerlendirilmesi konusu üzerinde durmuşlardır. Bir diğer çalışma da ise farklı bir bakış açısıyla, mobil uygulama kullanıcılarının şikâyetleri tespit edilmeye çalışılmıştır (Khalid, Shihab, Nagappan and Hassan 2015). Literatürde yer alan bu çalışmaların, mobil sağlık okuryazarlığının gelişmesine ve bu uygulamaların sürekliliğinin sağlanmasına katkısı yüksektir. Bu çalışmada ise, öğrencilerin eNabız mobil sağlık uygulamasına ilişkin bakış açıları değerlendirilmiş ve ayrıca uygulamanın sürekli kullanımına ilişkin öğrenci niyetleri belirlenmeye çalışılmıştır. Bu bağlamda elde edilen araştırma sonuçlarına göre; kadın katılımcıların ve sürekli ilaç kullananların e-Nabız uygulaması bilgi ve duyarlılık düzeylerinin daha yüksek olduğu belirlenmiştir. Ayrıca mobil uygulama derecelendirme ölçeği alt başlıkları olan katılım, işlevsellik, estetik ve bilgi kalitesi bağımlı değişkenleriyle kullanım niyeti bağımsız değişkeni arasında ilişki olduğu belirlenmiştir. Buna göre uygulamanın başarılı olduğu belirtilerek, katılımcıların kullanım niyetlerini olumlu etkilediği belirlenmiştir. Sonuç olarak elde edilen bulgular doğrultusunda, eNabız mobil sağlık uygulamasına farkındalığın yaratılması ve uygulamanın etkin bir şekilde kullanılmasının sağlanması söz konusu uygulamanın sürdürebilirliğini artıracaktır. $\mathrm{Bu}$ çerçevede e-Nabız uygulamasının fonksiyonel fayda sağlaması, bireylerin katılımını sağlayacak şekilde duygularına hitap etmesi önemlidir. Bunun yanı sıra uygulamadaki bilgilerin doğruluğu, menülerin basit, yazı tipinin anlaşılır ve görüntü kalitesinin yüksek olması uygulamanın kullanılırlığını arttıracak ve sağlık sisteminin daha hızlı ve kaliteli bir şekilde işlemesine yardımcı olacaktır.

Çalışmanın en büyük kısıtı, sadece Ankara Hacı Bayram Veli Üniversitesi Sağlık Yönetimi bölümü öğrencilerine yönelik gerçekleştirilmesidir. Gelecekteki çalışmaların farklı özelliklere sahip, geniş katılımcı gruplarıyla gerçekleştirilmesi, sonuçların karşılaştırılmasına olanak sağlayacaktır. Ayrıca gelecekteki çalışmalarda kullandığımız araştırma modeline yeni değişkenler eklenmesi daha kapsamlı açıklamaların yapılmasına imkân verecektir. 


\section{Kaynakça}

Arsand E., Froisland D. H., Skrovseth S. O., Chomutare T., Tatara N., Hartvigsen G. and Tufano J. T. (2012). Mobile health applications to assist patients with diabetes: lessons learned and design implications. Journal of Diabetes Science and Technology 6(5): 1197-1206.

Arslan E. T. ve Demir H. (2017). Üniversite öğrencilerinin mobil sağlık ve kişisel sağlık kaydı yönetimine ilişkin görüşleri. Aksaray Üniversitesi İktisadi ve İdari Bilimler Fakültesi Dergisi 9(2): 17-36.

Belyaev K., Sun W., Ray I. and Ray I. (2018). On the design and analysis of protocols for personal health record storage on personal data server devices. Future Generation Computer Systems 80: 467-482.

Brown III, W., Yen, P. Y., Rojas, M. and Schnall, R. (2013). Assessment of the health it usability evaluation model (health-ituem) for evaluating mobile health (mHealth) Technology. Journal of Biomedical Informatics, 46(6), 1080-1087.

Conroy, D. E., Yang, C. H. and Maher, J. P. (2014). Behavior change techniques in top-ranked mobile apps for physical activity. American Journal of Preventive Medicine, 46(6), 649-652.

De Mattos W. D. And Gondim, P. R. (2016). M-health solutions using 5g networks and $\mathrm{m} 2 \mathrm{~m}$ communications. IT Professional, 18(3), 24-29.

Demir, R. (2017). Medipol üniversitesi ögrencilerinin sağlık bilgi sistemleri ve e-nabız sistemine ilişkin farkındalık ve kullanım düzeylerinin belirlenmesi, (Yayımlanmamış Yüksek Lisans Tezi), İstanbul Medipol Üniversitesi, Sağlık Bilimleri Enstitüsü, İstanbul.

Enginkaya, E. (2019). Sağlık sektöründe dijital dönüşüm. M. Babacan (Ed), Dijital dönüşüm ekseninde işletme uygulamalarl, ss. 416, Ankara: Detay Yayıncılık.

Free, C., Phillips, G., Felix, L., Galli, L., Patel, V. and Edwards, P. (2010). The effectiveness of m-health technologies for improving health and health services: a systematic review protocol. BMC research notes, 3(1), 250.

Free, C., Phillips, G., Galli, L., Watson, L., Felix, L., Edwards, P., Patel V. and Haines, A. (2013). The effectiveness of mobile-health technology-based health behaviour change or disease management interventions for health care consumers: a systematic review. PLoS med, 10(1), e1001362. 
Güler, Ç. (2019). A structural equation model to examine mobile application usability and use. Bilişim Teknolojileri Dergisi, 12(3), 169-181.

Hamel, M. B., Cortez, N. G., Cohen, I. G. and Kesselheim, A. S. (2014). FDA regulation of mobile health technologies. The New England Journal of Medicine, 371(4), 372-379.

Huy N. P. and Vanthanh D. (2012). Evaluation of mobile app paradigms. In Proceedings of the 10th International Conference on Advances in Mobile Computing \& Multimedia, pp. 25-30.

Istepanian, R. S. and Lacal, J. C. (2003). Emerging mobile communication technologies for health: some imperative notes on m-health. In Proceedings of the 25th Annual International Conference of the IEEE Engineering in Medicine and Biology Society, IEEE Cat. No. 03CH37439, IEEE, 2003, September, Vol. 2, pp. 1414-1416.

Kalayc1, Ş. (2016). SPSS uygulamalı çok değişkenli istatistik teknikleri. 7.bask1, Ankara: Asil Yayın, 405-415.

Khalid H., Shihab E., Nagappan M. and Hassan A. E. (2015). What do mobile app users complain about? IEEE Software 32(3), 70-77.

Kıraç, R. ve Yılmaz, G. (2019). Yetişkinlerde e-nabız sistemi farkındalığının belirlenmesine yönelik bir araştırma. 3. Uluslararası 13. Ulusal Sağllk ve Hastane İdaresi Kongresi, 10-13 Ekim 2019, Sakarya, 1658-1668.

Kyriacou, E., Pattichis, M. S., Pattichis, C. S., Panayides, A. and Pitsillides, A. (2007). mHealth e-emergency systems: current status and future directions. IEEE Antennas and Propagation Magazine, 49(1), 216-231.

Lupton, D. (2013). Quantifying the body: monitoring and measuring health in the age of mhealth technologies, Critical Public Health, 23(4), 393-403.

Mechael, P. N. (2009). The case for mhealth in developing countries. Innovations: Technology, Governance, Globalization, 4(1), 103-118.

Merrell R.C., and Doarn C.R. (2011). Medical applications, mobility, and regulations. Telemed J E Health, 17:235-236.

Singh, A., Wilkinson, S. and, Braganza, S. (2014). Smart phones and pediatric apps to mobilize the medical home. TheJournal of pediatrics, 165(3), 606-610. 
Stoyanov, S. R., Hides, L., Kavanagh, D. J., Zelenko, O., Tjondronegoro, D. and Mani, M. (2015). Mobile apprating scale: a new tool for assessing the quality of health mobile apps. JMIR mHealth and uHealth, 3(1), e27.

Stoyanov, S. R., Hides, L., Kavanagh, D. J. and Wilson, H. (2016). Development and validation of the user version of the mobile application rating scale (uMARS). JMIR mHealth and uHealth, 4(2), e72.

T.C. Sağlık Bakanlığı (2020). E-nabız kişisel să̆lık sistemi. Erişim tarihi: 28.01.2020, https://enabiz.gov.tr/Yardim/Index.

Uyar, A. (2019). Tüketicilerin mobil uygulamalara ilişkin algılarının teknoloji kabul modeli ile değerlendirilmesi. İsletme Araştırmaları Dergisi, 11(1), 687-705.

Venkatesh, V. and Goyal, S. (2010). Expectation disconfirmation and technology adoption: polynomial modeling and response surface analysis. MIS Quarterly, 281-303.

Viswanath, K., Finnegan J.R. and Gollust, S. (2015). Communication and Health Behaviour in a Changing Media Environment. Health behaviour: Theory, research and practice, 5th Edition. Eds. Glanz, K., Rimer, B.K. and Viswanath, K., John Wiley\&Sons, 354.

Yeşiltaş, A. (2018). E-nabız uygulamasının kullanımını etkileyen faktörler. Să̆llk Akademisyenleri Dergisi, 5(4), 290-295.

Wang, Y., Greene, B. and Sun, L. (2020). An analysis and evaluation of quality and behavioral change techniques among physical activity apps in china. International Journal of Medical Informatics, 133, 104029, 1-7. 